\title{
Estimation of Surface Modification Methods Effect on Topography of Dental Implants by Using Metrological Observation Techniques
}

\author{
A.G. Bulutsuz ${ }^{a, *}$, Ç.Ü. Mercan ${ }^{b}$, G. Karapinar ${ }^{c}$, A.B. KatiboĞLu ${ }^{c}$ \\ AND M. LEWANDOWSKA ${ }^{d}$ \\ ${ }^{a}$ Yildiz Technical University, Faculty of Mechanical Engineering, Department of Mechanical Engineering, \\ 34349, Istanbul, Turkey \\ ${ }^{b}$ Istanbul Aydin University, Department of Oral and Maxillofacial Surgery, 34088 Florya, Istanbul, Turkey \\ ${ }^{c}$ Istanbul University, Faculty of Dentistry, Department of Oral and Maxillofacial Surgery, 34093, Istanbul, Turkey \\ ${ }^{d}$ Warsaw University of Technology, Faculty of Materials Science and Engineering, Warsaw, Poland \\ Over the last few decades the use of dental implants has been increasing everyday as a solution for partial or \\ full edentulism. The osseointegration process has to be fully completed to reach a prosthetic phase, so that patient \\ can start to use the dental implants functionally. One of the most important factors affecting osseointegration is the \\ surface properties of dental implants. Surface roughness of dental implant is vital to increase bone anchoring and \\ maintain the biomechanical stability. In addition to successful application of dental implants, rapid osseointegration \\ has also been desired as a favorable situation. It is demonstrated that there is a strong correlation between the \\ successful application and rapid osseointegration of dental implants and the surface morphology and characteristics \\ of dental implants. From this point of view, investigation of the surface morphology of implants has a vital \\ importance for manufacturers. The aim of our study was to evaluate the surface topography and homogeneity of \\ dental implants with different surface modifications by means of $2 \mathrm{D}$ and 3D observation methods.
}

DOI: 10.12693/APhysPolA.129.625

PACS/topics: 87.85.J-

\section{Introduction}

After the introduction of osseointegration concept by Branemark almost a half century ago, the use of dental implants has been increasing everyday as a solution for partial or full edentulism. Dental implant has become a routine treatment option in dentistry. The success of a dental implants is mainly based on the osseointegration that is defined as "the direct contact between the bone tissue and the dental implant surface, without fibrous tissue growing at the interface" $[1,2]$. The quality of direct contact between the implant and surrounding bone is very important for short- and long-term clinical success of dental implants [3, 4].

Implant surface roughness can be evaluated in various ways depending on the dimension of the measured surface features, such as macro, micro, and nano-topographies. The surface modification methods of implants can be classified into three categories: mechanical, chemical, and physical. These methods can be used to change the implant surface morphology, chemistry and structure. In order to improve the micro topography of the surface, many different advanced methods are being used by the implant manufacturers, such as titanium plasma spraying, acid-etching, grit-blasting, etc.

*corresponding author; e-mail: asligunaya@gmail.com
In this study titanium surfaces modified in various ways are investigated using stylus and optical profilometers. Surface topography and homogeneity of titanium specimens modified using different methods are investigated by means of $2 \mathrm{D}$ and $3 \mathrm{D}$ observation techniques.

\section{Materials and methods}

Ti implant samples were prepared from 99.5\% pure titanium of grade 4 (CP Ti G4). All specimen groups were modified using blasting method in following ways:

1. Specimens of the first type were blasted with titanium oxide $\left(\mathrm{TiO}_{2}\right)$ particles under a blast pressure of 4 Bar for 40 seconds. The particles had approximately $150 \mu \mathrm{m}$ in diameter.

2. Specimens of the second type were blasted with HA/B-TCP (Hydroxyapatite/Biphasic Calcium Phosphate). According to the material technical report, the composition includes $>65 \%$ hydroxyl apatite, $<35 \%$ b-TCP, A-TCP and TTCP, $<5 \%$ Ca-P materials. More than $95 \%$ of the blasting particles were bigger than $300 \mu \mathrm{m}$. The blast pressure was 3.5 Bar, blasting time was 50 second and a $1.5 \mathrm{~mm}$ nozzle diameter was selected.

3. Specimens of the third type were blasted with Biphasic Calcium Phosphate particles with radius smaller than $100 \mu \mathrm{m}$. The blasting pressure 
was 3.5 Bar. The specimens were blasted for $40 \mathrm{sec}-$ onds. After BCP blasting, to achieve a hybrid surface the specimens surfaces were etched in a hydrofluoric acid bath for 12 seconds.

During the blasting procedure all specimens were attached to a rotating table to produce a homogeneously blasted surface.

TABLE I

Roughness values of specimen surfaces observed using optical and stylus profilometers.

\begin{tabular}{c|c|c}
\hline \hline & $\begin{array}{c}\text { Stylus profilometer } \\
{[\mu \mathrm{m}]}\end{array}$ & $\begin{array}{c}\text { Optical profilometer } \\
{[\mu \mathrm{m}]}\end{array}$ \\
\hline $\mathrm{TiO} 2$ & 1.482 & 1.678 \\
$\mathrm{BCP}$ & 1.719 & 1.875 \\
Hybrid & 1.132 & 1.32
\end{tabular}

In order to quantify topography changes for each treatment type, the roughness measurements with optical profilometer were performed (Table I). Optical micrographs of surface topographies were obtained using a Veeco Wyko NT9300 optical profilometer. Titanium surfaces were prepared individually and 2D roughness measurements were performed using the contact stylus profilometer (Mitutoyo SJ 400) according to the ISO 4287. During the measurement procedure Gauss filter with $0.8 \mathrm{~mm}$ cut off value, and $0.8 \mathrm{~mm}$ length was selected for assessing the $2 \mathrm{D}$ profile roughness measurement. Five repetitive measurements were made on each specimen. The average values of these measurements are given in Table I.

\section{Results and discussion}

The surfaces modified using different blasting methods were observed using optical profilometer, as illustrated in Table II. The results indicate that there are critical morphological differences between the samples. According to the optical observation, the blasted surfaces and the residual particles can be easily identified in larger peaks and valleys of the profiles. Surface irregularities and roughness increase proportionally with the increase in blasting particle size. Blasting creates valleys in the damaged substrate and the residual blasting material. It is assumed that acid etching procedure decreased residual materials on the surface. It can be concluded from optical profilometer profile images that BCP surfaces and $\mathrm{TiO}_{2}$-blasted surfaces present higher irregularity of profiles but BCP surface images indicate wider cavities between the peaks. Acid etched BCP surface points out smaller surface roughness with smaller peak and valley and a homogenous surface. All specimens from the blasted groups had irregularities in the form of sharp edges and peaks resulted from surface modification procedure. Acid etching procedure decreased these irregularities. Moreover, on the micron level flat areas have been observed. These changes have not been observed in the macro level.
TABLE II

Optical profilometer observations of specimen surfaces.

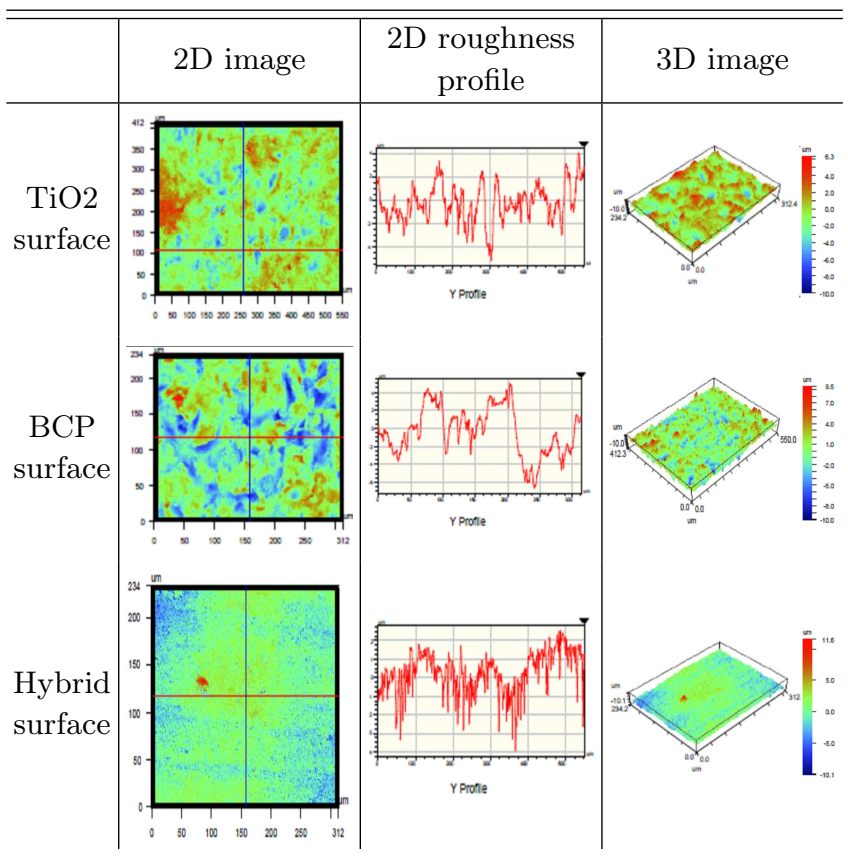

The roughness of the surfaces was quantified using roughness value defined as the arithmetic mean deviation, $R_{a}$. The results of these calculations are presented in Table I for two profilometers. The highest roughness was obtained for the second type of samples, i.e. blasted with BCP particles with a size larger than $300 \mathrm{~nm}$. The smallest roughness was found in the samples modified using the hybrid method. Roughness values measured by optical profilometer were slightly higher than those obtained using stylus profilometer, but in general the results from both methods are consistent.

One of the most important factors affecting osseointegration is the surface properties of dental implants [5-6]. There are numerous reports that reveal the surface roughness as one of the most important factors affecting the rate of osseointegration [7-9]. Roughened surfaces effect positively osseointegration procedure $[1,10,11]$. Roughened surface of implant enables tissue attachment to the implant that results in a mechanical locking of implant inside the body. According to the literature, values between 1-3.9 $\mu \mathrm{m} S_{a}\left(S_{a}: R_{a}\right.$ of an area) are optimal for osseointegration [11-13]. Another study suggests $4.5 \mu \mathrm{m} R_{a}$ as the optimal surface roughness [14]. In literature there are different optimal roughness values, they vary depending on mechanical and chemical properties of the implant surface.

\section{Conclusions}

The applied surface blasting resulted in relatively high roughness. The specimens had irregularities in the form of sharp edges and peaks, resulted from surface modification procedure. Acid etching procedure decreased 
surface roughness. Moreover, on the micron level, flat areas have been observed. These changes have not been observed in the macro level, whereas "macrotexture" consisted of 10-30 $\mu \mathrm{m}$ waviness. Roughness values measured by optical profilometer were higher than those of stylus profilometer. Both of these two measurement techniques concluded that BCP had the highest and the hybrid surface had the lowest surface roughness values. In future work cell culture test will be applied to investigate the impact of the roughness values between 1-3 $\mu \mathrm{m} R_{a}$ and of the surface modification method on the osseointegration performance of implants, in order to find the optimal surface roughness.

\section{Acknowledgments}

The authors would like to thank Dental Implant KA Mode Medical for their experimental material support.

\section{References}

[1] R. Liu, T. Lei, V. Dusevich, X. Yao, Y. Liu, M.P. Walker, Y. Wang, L. Ye, J. Prosthodont. 22, 641 (2013).

[2] P.I. Brínemark, B.O. Hansson, R Adell, U. Breine, J.J. Lindström, O. Hallén, A. Ohman, Scand. J. Plast. Reconstr. Surg. Suppl. 16, 1 (1977).

[3] T. Albrektsson, P.I. Branemark, H.A. Hansson, J. Lindstrom, Acta Orthop. Scand. 52, 155 (1981).
[4] L. Le Guéhennec, A. Soueidan, P. Layrolle, Y. Amouriq, Dent. Mater. 23, 844 (2007).

[5] Y.T. Sul, B.S. Kang, C. Johansson, H.S. Um, C.J. Park, T. Albrektsson, J. Biomed. Mater. Res. A 89A, 942 (2008)

[6] T. Jarmar, A. Palmquist, R. Brånemark, L. Hermansson, H. Engqvist, P. Thomsen, Clin. Implant Dent. Relat. Res. 10, 11 (2008).

[7] A. Wennerberg, C. Hallgren, C. Johansson, S. Danelli, Clin. Oral Implants Res. 9, 11 (1998).

[8] A. Wennerberg, T. Albrektsson, B. Albrektsson, J.J. Krol, Clin. Oral Implant Res. 6, 24 (1995).

[9] M.B. Rosa, T. Albrektsson, C.E. Francischone, H.O.S. Filho, A. Wennerberg, J. Appl. Oral Sci. 20, 550 (2012).

[10] M.M. Shalabi, A. Gortemaker, M.A.V. Hof, J.A. Jansen, N.H. Creugers, J. Dent. Res. 85, 496 (2006).

[11] K. Vandamme, I. Naert, J. Vander Sloten, R. Puers, J. Duyck, J. Periodontol. 79, 150 (2008).

[12] A. Wennerberg, T. Albrektsson. Int. J. Oral Maxillofac. Implants 15, 331 (2000).

[13] A. Wennerberg, T. Albrektsson, Clin. Oral Impl. Res. 20, 172 (2009).

[14] C. Aparicio, A. Padrós, F.-J. Gil, J. Mech. Behav. Biomed. Mater. 4, 1672 (2011). 